\title{
PLC BASED AUTOMATIC FUEL DISPENSING SYSTEM USING RFID TECHNOLOGY
}

\author{
Shreedhar M.B \\ Department of Mechanical Engineering \\ Malnad college of Engineering, Hassan, karnataka, \\ India
}

\author{
B.S. Shivashankara \\ Assistant Professor \\ Department of Mechanical Engineering \\ Malnad college of Engineering, Hassan, karnataka, \\ India
}

\begin{abstract}
Nowadays the time is a precious thing that nobody wants to experience a time delay in any activities of their day to day life. In this tightly packed daily schedule of the consumers of the petrol bunk, there is an urge to go for an automated petrol dispensing system by eliminating manual mode of fuel dispensing system. In this concern the present work is an attempt to automate the fuel dispensing system by using PLC, RFID technology as advanced automation tools to reduce surge of vehicles in front of petrol bunks to refill their vehicle's fuel by reducing overall fuel dispensing time compared with manual mode of operation
\end{abstract}

Keywords- PLC, RFID, HMI

\section{INTRODUCTION}

India is a large country with over 1.2 billion population. Nowadays the number of motor vehicles is increasing at very fast rate. Due to this the fuel consumption is also increasing day by day. So in these situations, it is becoming very time consuming to pump the petrol to each vehicle.

In the current days the petrol pumps are operated manually which is time consuming and also require man power. Another problem in manual method of fuel dispensing is that taking money and giving change by hand is time consuming.

Because of the above mentioned disadvantages there is a need for an automatic system for dispensing the fuel in which the consumer itself will pump the required amount of petrol without any workers involved. As it is the $21^{\text {st }}$ century with advanced automation tools and living in the digital world, it is not a difficult task for automating the present day petrol dispensing system.

For automating the petrol dispensing system, there are so many ways. One of the best methods is using the RFID technology which is similar to ATM. PLC can be used as a main controlling unit. The main advantage of using PLC is they are rouged and it can be used in harsh environments and at higher temperature. As petrol pumps are prone to leakage and fire, PLC can be very much appropriate to use in place of microcontroller.
Programmable LOGIC Controller (PLC) is a device which is used in the field of automation to control industrial processes. This works on certain logic programmes which are written based on the process need to be controlled using specific software and downloaded into the PLC in order to control the process. The capacity of the PLC is determined based on the number of inputs and outputs. Ladder diagram is the most commonly used method of PLC programming as it is easy to construct and can be understood easily compared to other methods.

Radio Frequency Identification (RFID) is used to read and capture the information which is stored on the RFID tags by the use of radio waves. It consists of two parts a tag and a reader. Tag consists of microchip for processing and there will be antenna in the tag to transmit and receive the signal.

\section{METHODOLOGY}

In this Automated Petrol dispensing system PLC is used to control the process, the PLC used in the system is Delta (14ss2). By adding PLC-based Control units to the system configuration, PLC process control functions can be simply added on to the basic functions which is installed in the PLC. It can be used for components that it is compatible with such process control system in which it was used before. With the PLC Installation System, analog processing is carried out by the loop control section or the loop control unit, and ladder diagram processing is handled by the processor. Communication between the two sections is done using bits of memory. It is easy to use PLC program since analog processing and ladder diagram can be separated, hence the engineering process to build the system is facilitated. The PLC unit utilizes a variety of different data including user programs, I/O Memory data and commands, processor unit and Special I/O units, parameters and rregistered I/O table information etc. All these data that is used by the PLC is stored in the memory space within the CPU unit. The I/O memory area is accessed by command operands. 


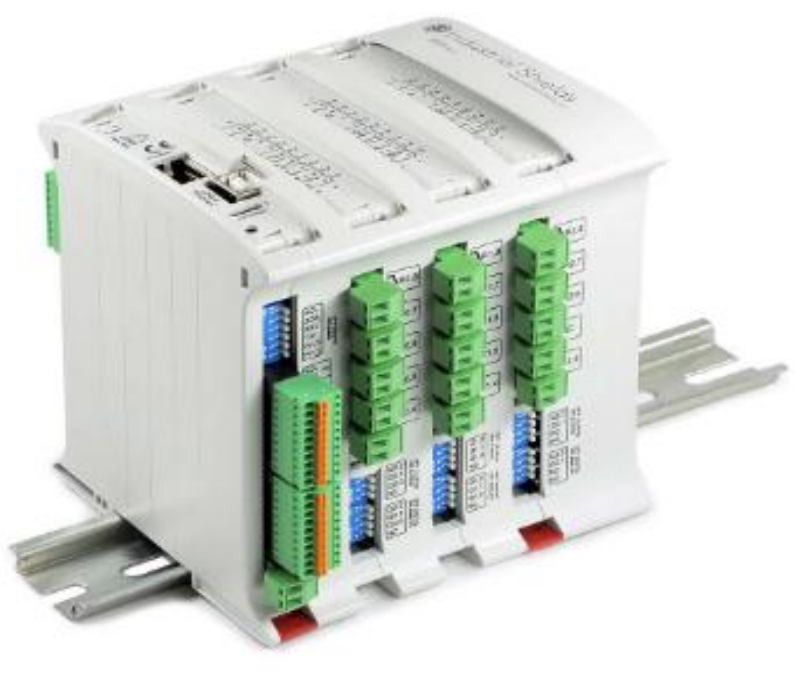

Fig -1: PLC unit

RFID uses radio frequency to automatically identify and track tags attached to objects. The RFID cards contain electronicallystored information. It consists of a tag and a reader. The tag is made from silicon material inserted with microchip and antenna to transmit and receive radio signals. The reader is used to sense the card using radio signals. Another advantage of RFID is that the tag need not be within the exact line of the reader like barcode reader.

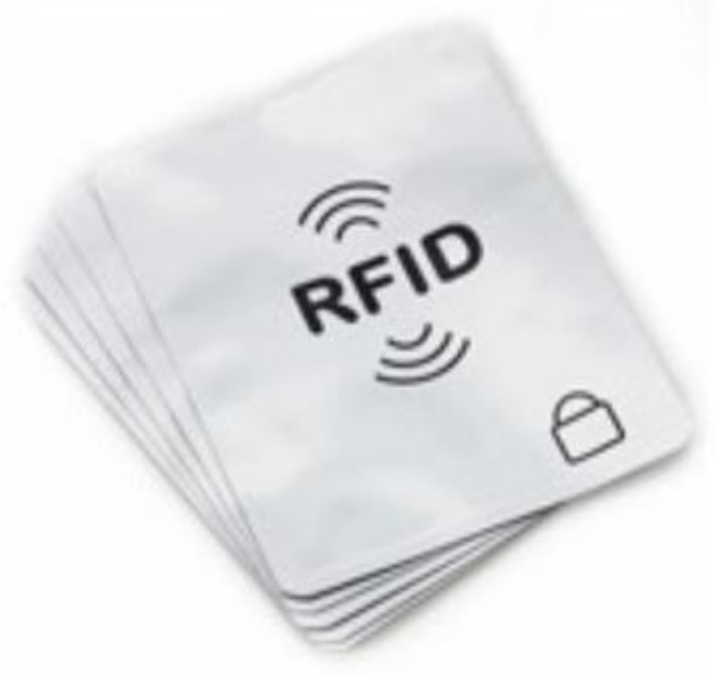

Fig -2: RFID card

\section{BLOCK DIAGRAM}

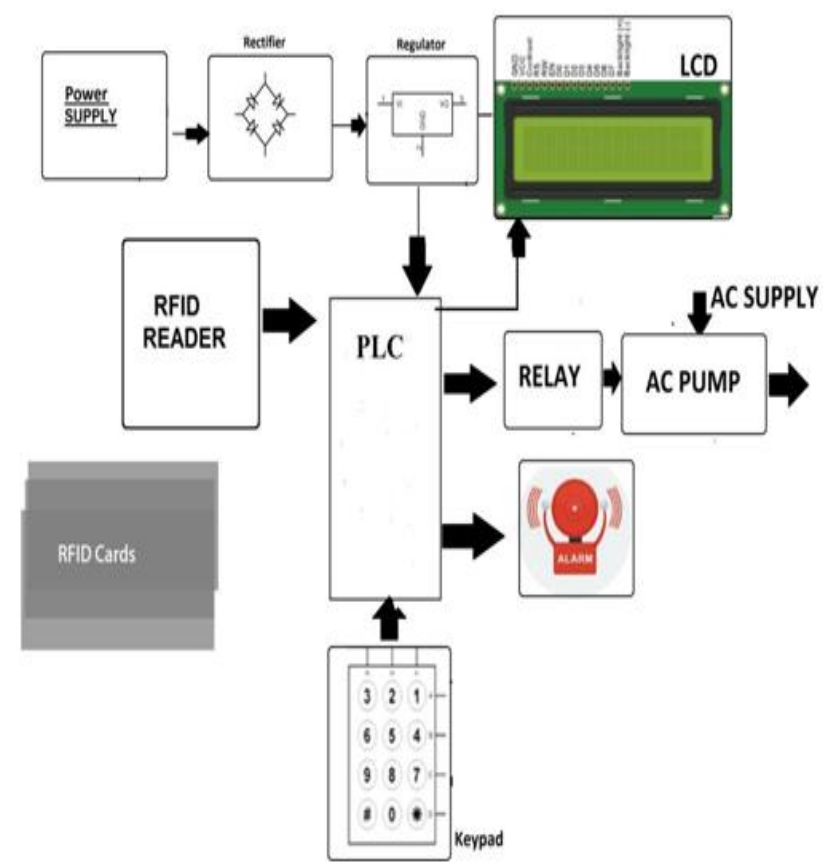

Fig -3: Block diagram of fuel dispensing system

Automatic fuel dispensing system is proposed to reduce human work and develop a self operated mechanism and to implement the task in certain sequence. This system operates automatically and take lesser time to operate. The proposed system is uses Programmable Logic Controller (PLC) to control the processes in petrol bunk. The system uses the RFID concept for monitoring and controlling the process

The Logical cycle for the petrol bunk processes are programmed in Ladder Diagram Language and downloaded to the PLC. The user can interact with the system and enter enter the amount using Human Machine Interface. As HMI transfer the values entered by the user to the PLC and the PLC will control the processes automatically.

In this proposed system the RFID concept is used just like an ATM card which can be recharged with amount. Once the consumer goes to the fuel station, the RFID card is swiped and required amount is entered using HMI screen. IF the card has required of money then the fuel will be dispensed based on the amount entered

\section{RFID consists of two parts}

1. RFID tag: It consists of a microchip with an antenna which is mounted on a substrate material.

2. Reader: It is used to send and receive signals and it communicates with tag using radio signals. 
International Journal of Engineering Applied Sciences and Technology, 2019

Vol. 4, Issue 1, ISSN No. 2455-2143, Pages 54-57

Published Online May 2019 in IJEAST (http://www.ijeast.com)

III. RESULTS AND DISCUSSIONS

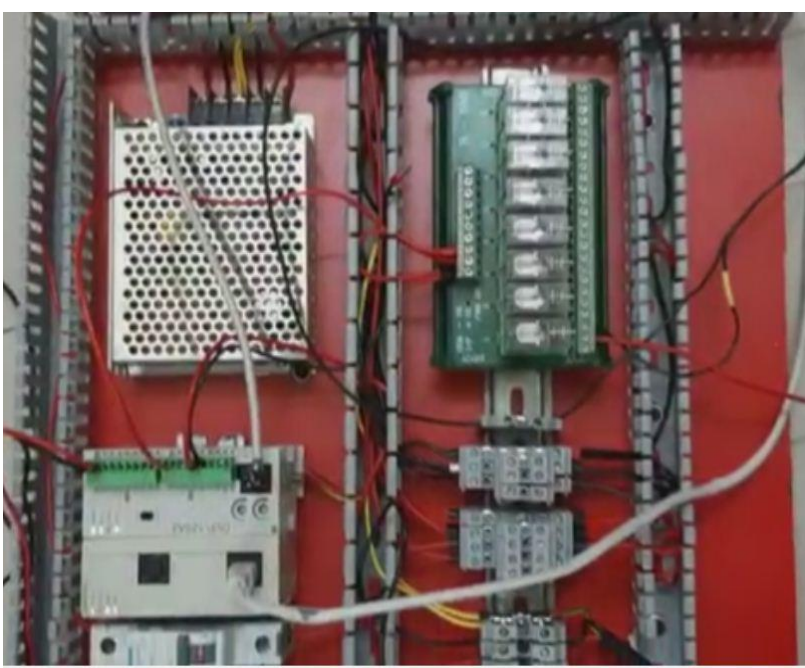

Fig -4: Experiental setup

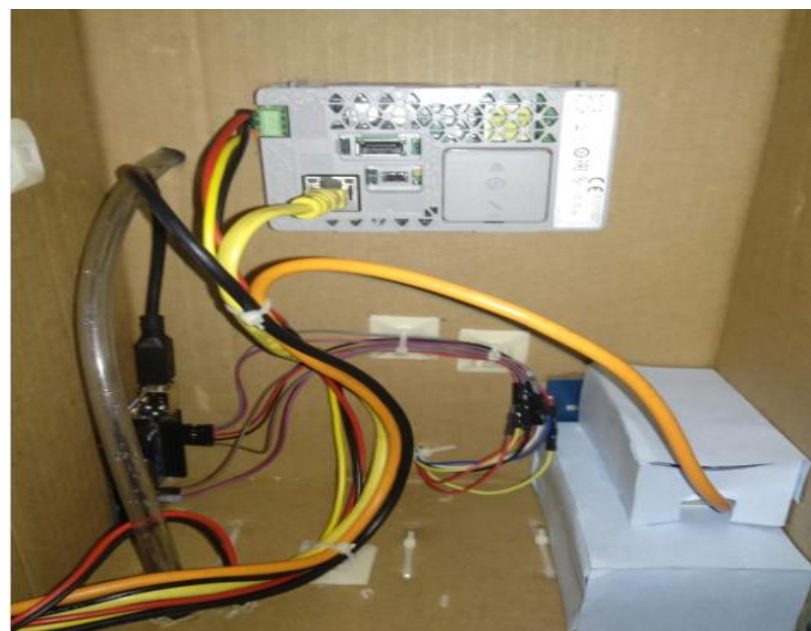

Fig -5: Arduino setup

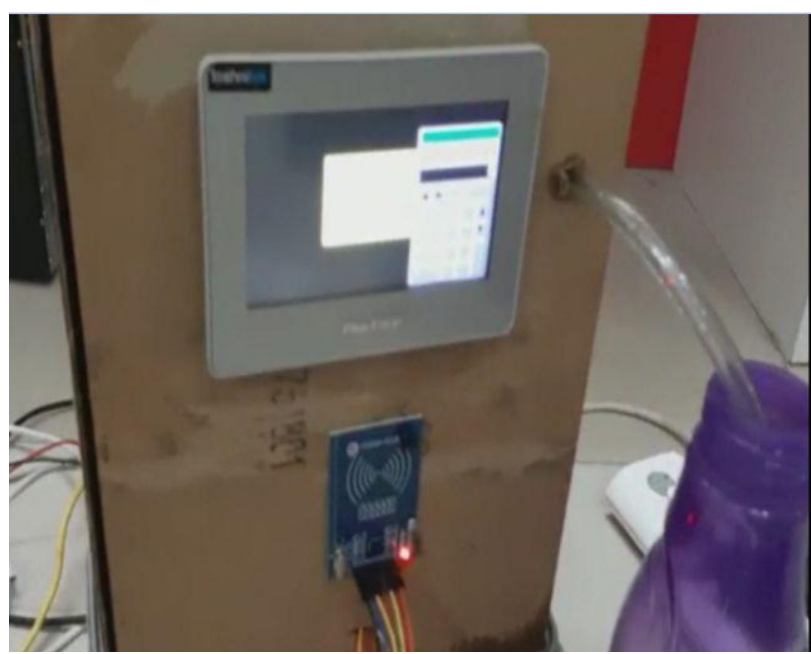

Fig -6: HMI screen

\section{Turn ON power supply and swipe card}

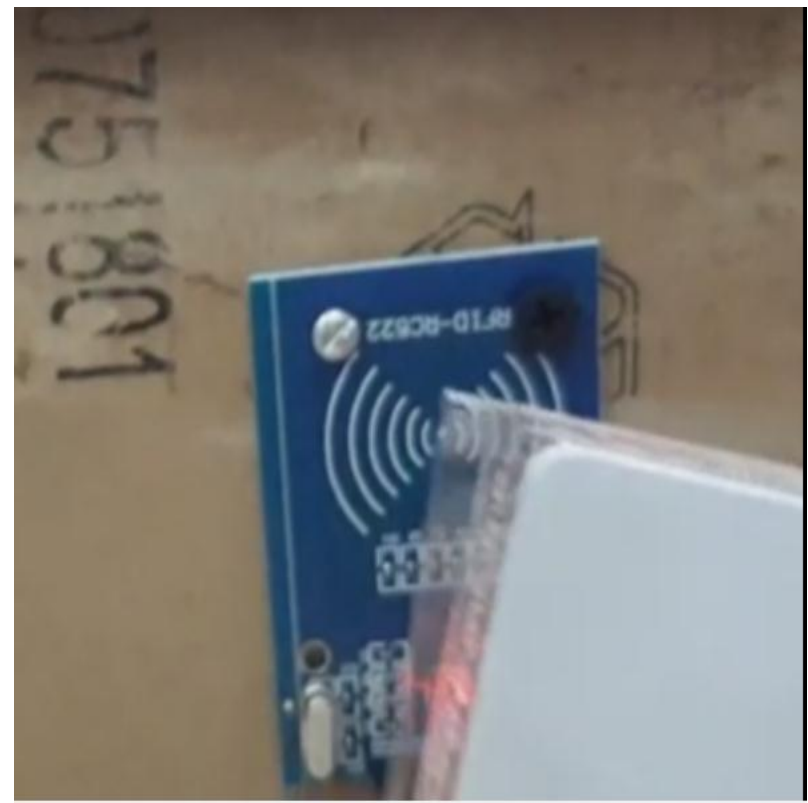

Fig -7: Swiping of card

Once the power is switched ON the HMI screen will get ON and asks for swiping the card as shown in figure 7 . Once the card is authenticated, then it asks to enter the amount.

\section{Enter the amount}

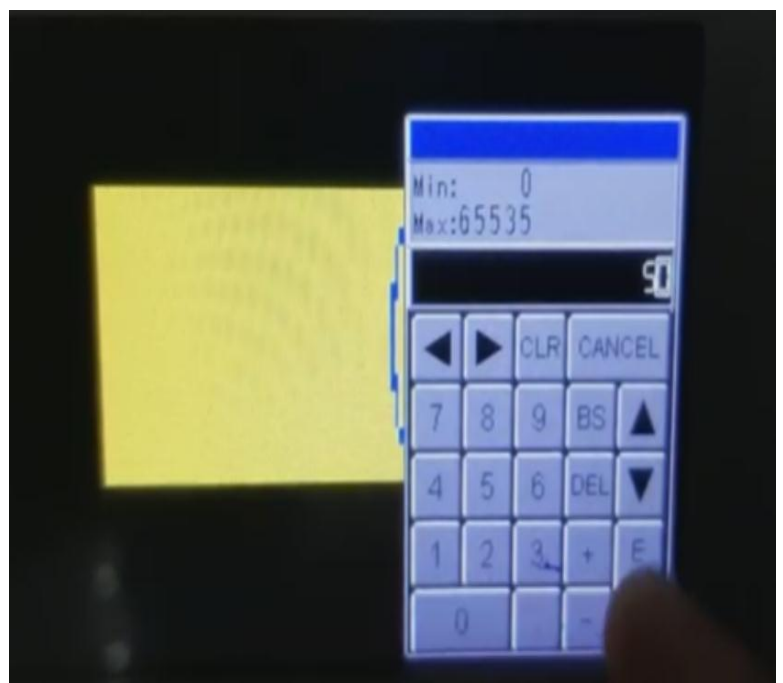

Fig -8: Amount entry

After authentication, next step is to enter the amount of money as shown in figure 8 . Based on the money, the required amount of petrol will be dispensed. The amount is entered in the HMI screen. After entering the amount, the enter button should be pressed. Then the push button should be pressed to start the pump. Only if the card is sensed properly the pump will ON. 


\section{International Journal of Engineering Applied Sciences and Technology, 2019 \\ Vol. 4, Issue 1, ISSN No. 2455-2143, Pages 54-57 \\ Published Online May 2019 in IJEAST (http://www.ijeast.com)}

\section{Filling the petrol}

Once the amount is entered, the PLC gets the signal from the HMI, then PLC gives signal to the pump to ON and thus the required amount of petrol is filled.

\section{IV.CONCLUSION}

The system is very useful in refilling the fuel in less time and maximum number of vehicles can be filled with fuel. The Automatic fuel dispensing system project also reduces the hand to hand transaction of the money. It reduces the man power by making the entire process of petrol pumping automatic. Thus the overall aim of the proposed system is to give good relationship between man and machine. The project provides low maintenance cost and controlling is easier.

\section{REFERENCE}

[1]. Priyanka ,A. Gaikwad,G. Shubhangi ,S. Pallavi ,S. and Pratibha ,K. et al(2017), 'Automation in Petrol Bunk using RFID and GSM', Journal of Filling Station, Volume.4 pp.12-19.

[2]. Andrew Rae ,G.(2016), 'Helping the Operator in the Loop: Practical Human Machine Interface Principles for Safe Computer Controlled Systems', Journal of HMI Interface, Volume.27 pp.167-192.

[3]. Anilkumar ,G. Jayakrishnan, B. and Kusuma ,V.( 2016), 'Design of Unmanned Petrol Bunk System Using RFID Technology', Journal of Microcontrollers in Automation, Volume.6 pp.187-198.

[4]. BangalSwapnil , P.(2016), 'Unmanned Fuel Station', Journal of Man Machine Automation, Volume.23 pp.445-454.

[5]. Gluckstad,A. and Jesper,V.(2016), 'Light Robotics:a new tech-nology and its applications', Journal of Robotics, Volume.5 pp.17-29.

[6]. Aniket Jadhav,H. Rajan Pawar,S. Priyanka Pathare,M. and Kishori Pawar,D. et al (2015), 'Multi-Automized Fuel Pump With User Security', Journal of Automizations, Volume.31 pp.117-132.

[7]. Paul Gruhn, P.E.(2015), 'Human Machine Interface (HMI) Design', Journal of HMI Rules \& Design, Volume.11 pp.17-32.

[8]. Pandit ,P.A. and Patil ,A. (2014), 'Automated Water Supply with Monitoring the Performance System', Journal of Water Distribution, Volume.4 pp.12-19.

[9]. Ekta Tripathi, V. Abdul Bari ,S. and Gupta ,P.K.(2012), 'The PLC Based Approach for Automation of Power Distribution in Radar', Journal of Automation Approaches, Volume.15 pp.217-249.

[10]. Aishwarya Jadhav ,J. Lajari Patil , A. and Sonawane Q.(2013), 'Smart Automatic Petrol Pump System',
Journal of Unmanned Petrol Pump, Volume.5 pp.325354.

[11]. Michael Foster ,R. George ,M. and Robert Melendy George ,D.(2010), 'A Review of Programmable Logic Controllers in Control Systems Education', Journal of Implementing PLC,Volume.22 pp.421-425.

[12]. Michael Sam,J. and McDonald ,D. (2010), 'Active Research Topics in Human Machine Interfaces', Journal of Intelligent System \& Robotics, Volume.17 pp.45-53. 